\title{
Episteme dos métodos
}

\section{Resumo}

Este artigo tem por objetivo analisar aspectos em torno da ciência (episteme) dos métodos que resultaram do estudo intitulado, "Pesquisa Educacional na Amazônia: Um estudo sobre epistemologias e metodologias que servem de suporte à produção do conhecimento em educação nas Universidades da Amazônia Paraense", desenvolvido no ano de 2011, por ocasião de meu Estágio de Pós-Doutorado no Grupo PAIDEIA da FE-UNICAMP, e que apresenta como fundamentação o quadro de referências teórico-conceituais e metodológicas sobre 'epistemologia e teorias da educação' que faz parte da obra de Silvio Sánchez Gamboa.

Palavras-Chave: Episteme; Métodos; Pesquisa em educação.

\begin{abstract}
This article aims to analyze issues around the science (episteme) methods that resulted from the study entitled, "Educational Research in the Amazon: A study of epistemologies and methodologies that support the production of knowledge in education at the University of Pará in the Amazon" developed in 2011, during my Internship Postdoctoral Paideia group of FE-UNICAMP, and presents the framework as the basis of references theoretical, conceptual and methodological about 'epistemology and theories of education' which is part of work of Silvio Sanchez Gamboa.
\end{abstract}

Keywords: Episteme; Methods; Research in education. 


\section{Introdução}

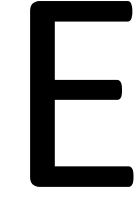

sta exposição conta com o fundamento teórico-conceitual extraído do Projeto intitulado, A Pesquisa Educacional na Amazônia: Um estudo sobre epistemologias e metodologias que servem de suporte à produção do conhecimento em educação nas Universidades da Amazônia Paraense, desenvolvido entre 2010-2011, durante meu Estágio de PósDoutorado no Grupo PAIDEIA da FE-UNICAMP, (a apresentação pública dos resultados da pesquisa aconteceu no dia 30 de março de 2012 no evento denominado Colóquio de Epistemologia e Educação, promovido Pelo Grupo de Pesquisa PAIDEIA e FE - UNICAMP), essa pesquisa tomou como base a coleção de obras, o conjunto de teses e as sínteses apresentadas por Silvio Sánchez Gamboa, que demarcam historicamente desde os anos 80 do século passado até o tempo atual, um campo de estudos sobre Epistemologia e Teorias da Educação demonstrando as formas de Construção e Produção do Conhecimento válido na área educacional.

As obras de Silvio Gamboa, ao longo desse tempo-espaço servem de suporte teórico e metodológico a várias pesquisas em diversas Regiões do Brasil e em diversos Países da América Latina, o que pela presença histórica, política, social e acadêmico-científica de seus estudos e pesquisas, venho denominando de Paradigma Gamboa da Pesquisa em Educação.

O outro aspecto a ser considerado como referência desta exposição é a própria Conferência de Abertura do IV EPISTED intitulada “A Produção do Conhecimento em Educação: Teorias e Métodos", proferida pelo Dr. Silvio Gamboa.

Então, a partir do quadro de referências apresentado, optei por um recorte para nosso debate que diz respeito à Episteme dos Métodos, com a pretensão de introduzir um diálogo sobre a ciência (episteme) que temos ou não do caminho (método) de uma pesquisa em educação quanto ao seu fundamento epistemológico. 


\section{Desenvolvimento}

Os estudos e pesquisas de Silvio S. Gamboa, que formam o que denominamos de Paradigma Gamboa, desdobram-se por meio de uma vigorosa composição teórico - conceitual como resultado da análise crítico dialética de grandes obras de fundamento como: Marx, Kosik, Piaget, Lapati, Kopnin, Goldmann, Bachelard, Adorno, Habermas, Thiollent, entre outros autores, seguida da investigação empírica dos problemas em torno da produção do conhecimento válido em educação, vislumbrando em seu trabalho, especialmente, no estudo intitulado "Epistemologia da Pesquisa em Educação", a construção da pesquisa por meio de Núcleos e Linhas, e reforçando com suas teses o debate iniciado pela ANPED (1988).

As linhas de pesquisa referem-se fundamentalmente a campos problematizadores que desafiam o conhecimento ou exigem estudos aprofundados em torno dos quais agrupam-se interesses comuns dos investigadores. A nosso entender a denominação de núcleos ou linhas de pesquisa é mais apropriada para indicar essa mudança de concepção dos cursos de pós-graduação do que outras como núcleos temáticos, eixos temáticos, áreas temáticas, etc., A mudança de eixo de área de concentração para núcleos de pesquisa, coloca em destaque a pesquisa. A pesquisa sugere problematização, processos de busca, qualificação de questões, dinâmica do conhecimento; o tema sugere organização bibliográfica, sistema de abstrações, conhecimento dado. Pesquisam-se problemas e não temas. As tematizações podem ser resultados de pesquisas ou maneiras de organizar abstrações. As problematizações criam a tensão da busca, e os desafios para a construção do conhecimento. Problematizar está mais próximo da pesquisa que as tematizações (Gamboa, 1996, p. 77).

A substância do trabalho de Gamboa é a dialética materialista não no sentido totalizante da visão "ortodoxa" stalinizada, mas fundada no sentido da razão crítica, que confronta os contrários no contexto da sociedade humana onde a problemática educacional se apresenta e as contradições do ser construtor do conhecimento, em sua práxis, na parte interna e nas relações que se travam no campo externo as instâncias e instituições que produzem o conhecimento válido em educação. Então, cabe a "tensão da 
busca" a partir do problema, que pode começar com a indagação (investigação filosófica) da frequência de um elemento que se destaca no "todo estruturado" da área educacional.

O discurso epistemológico encontra na filosofia seus princípios e na ciência seu objeto. Tem como função não só resolver o problema geral das relações entre filosofia e as ciências, mas também servir de ponto de encontro entre elas. Esse encontro só é possível em uma prática concreta, portanto, quando falamos de epistemologia da pesquisa o fazemos com base em um exercício concreto nesta área, buscando instrumentos analíticos na filosofia" (Gamboa, 2008, p.26).

Esse "todo estruturado" avança e progride por entre a base material e as contradições que lhe servem de substância histórica, e inauguram a multiformidade das instituições sociais, culturais e científicas, e seus respectivos equipamentos de produção e desenvolvimento.

Em uma de suas teses da década de noventa do século passado, Gamboa apresenta um caminho para construção do conhecimento válido por meio da pesquisa:

As pesquisas com abordagens crítico-dialéticas criticam fundamentalmente a visão estática da realidade implícita nas anteriores abordagens. Visão esta que esconde seu caráter conflitivo, dinâmico e histórico. A racionalidade crítica, presente nessa abordagem, busca desvendar não apenas o 'conflito das interpretações', mas o conflito de interesses que determinam visões diferenciadas de mundo. Essas pesquisas manifestam um 'interesse transformador' das situações ou fenômenos estudados, resgatando sua dimensão sempre histórica e desvendando suas possibilidades de mudança (Gamboa, 1996, p. 113).

A realidade é corrente em seu caráter histórico. As noções positivistas de "uma visão estática", ordenada como etapa, para a dinâmica social, camuflam e naturalizam as contradições, e anulam a possibilidade de mudança, que um estudo e pesquisa podem vir a gerar no campo das ciências humanas e sociais, onde encontramos a área da educação, então, o caminho de construção do conhecimento válido em educação passa por uma 
orientação voltada para uma abordagem epistemológica crítica levando em consideração que "as ciências sociais não se podem limitar a relações entre magnitudes estáticas, pois essas exigem abordagens mais amplas que considerem o tempo como processo e não só como um dado, uma data, uma variável ou faceta" (Gamboa, 2008, p. 41).

As opiniões relativas à cognoscibilidade ou incognoscibilidade da concreticidade, como conhecimento de todos os fatos, baseiam-se na concepção empírico-racionalista segundo a qual o conhecimento se realiza mediante um método de análise e soma, cujo postulado é constituído pela representação atomística da realidade como congérie de coisas, processos e fatos. Ao contrário, no pensamento dialético o real é entendido e representado como um todo que não é apenas um conjunto de relações, fatos e processos, mas também a sua criação, estrutura e gênese. Ao todo dialético pertence a criação do todo e a criação da unidade, a unidade das contradições e a sua gênese (Kosik, 2002, p. 51).

O tratamento do objeto de estudo no campo sócio-histórico deve seguir uma "hermenêutica", que não fica presa a forma de abordagem e procedimentos de medida ou de quantificação - no caso do processo de pesquisa em educação, a medida deve gerar a qualificação, isto é, quantitativo e qualitativo estão implicados entre si quando se trata de produzir conhecimento válido nesse campo.

Na pesquisa em ciências humanas e ciências sociais, frequentemente são utilizados resultados e dados expressos em números. Porém, se interpretados e contextualizados à luz da dinâmica social mais ampla, a análise torna-se qualitativa. Isto é, na medida em que inserimos os dados na dinâmica da evolução do fenômeno e este dentro de um todo maior compreensivo, é preciso articular as dimensões qualitativas e quantitativas em uma inter-relação dinâmica, como categorias utilizadas pelo sujeito na explicação e compreensão do objeto (Gamboa, 2001, p.106).

A explicitação do objeto de estudo devidamente situado deve seguir os elementos característicos da "razão crítica" para apreensão no território 
movediço das contradições de possíveis sínteses que representem na materialidade do processo histórico, o andamento e o encadeamento do fenômeno, quanto às dimensões e as dinâmicas que estão presentes na concreticidade, este movimento é paradigmático, e se renova dialeticamente a partir de núcleos teóricos consolidados historicamente, mas, que não são absolutos e sectários, e estão abertos às "revoluções".

A Teoria Paradigmática de Gamboa, nos remete entre outras questões, a considerar na projeção de uma investigação o aprofundamento epistemológico, para uma clareza em relação as diversas abordagens que fazem parte das teorizações críticas sobre o conhecimento científico, atentando para o método (caminho) que também movimenta a episteme, em cada elemento que o fundamenta como percurso lógico da pesquisa. Porém, o que acontece de uma forma geral, por ocasião do planejamento de uma pesquisa é que atentamos com maior intensidade à construção da fundamentação por meio de referências bibliográficas para composição do núcleo teórico-conceitual, que facilite a revisão da literatura e a construção do estado do conhecimento, porém, a maioria das vezes, secundarizamos e não damos a mesma importância aos fundamentos do método, isto é, ficamos na superficialidade da composição de procedimentos meramente associados as técnicas de investigar fenômenos, tornamos o método (a metodologia de pesquisa) um capítulo mecanicista.

Assim, ao colocarmos as conceituações sobre o caminho em segundo plano, deixando o percurso da investigação sem a sua devida episteme (ciência), corremos o risco de comprometer toda arquitetura do andamento da investigação, porque é na trilha de pesquisa que movimentamos atitudes, comportamentos, emoções, conceitos, concepções, teorias, procedimentos, e instrumentalizamos a busca de respostas sobre a indagação central, que serve de norte para um ponto objetivo de conclusão, mesmo que essa plataforma final da síntese encontrada pelo estudo, apresente algumas certezas e muitas contradições.

A construção do conhecimento é um movimento de complexidades conceituais e metodológicas, e o seu resultado não é absoluto em si, nem na área de ciências exatas, com seu estatuto epistemológico amadurecido e a 
sua uniforme estruturação lógico-matemática quando da composição de seus estudos, a "Teoria da Relatividade", está cada dia mais viva e atualizada comprometendo a hegemonia dessa visão linear (2 mais 2 igual a 4) dos que acreditam na cultura da síntese absoluta, como resultado de uma pesquisa científica, mas, mesmo nas Ciências Humanas, que não apresenta um estatuto epistemológico claro e por isso aparentemente aberta a todo tipo de exercícios baseados no discurso espontâneo e no modismo, o trânsito por suas vias que congregam uma série de disciplinas e áreas de conhecimento hermenêuticas, que acabam por gerar um terreno teórico-conceitual arenoso e poroso de múltiplas interpretações, torna-se redobrada a necessidade de se investir em um caminho (método) bem teorizado quanto a sua epistemologia, porque o contrário, pode remeter o pesquisador a resultados finais tautológicos e sem originalidade dentro de sua área temática ou de sua linha de pesquisa.

A pesquisa em educação na Universidade Pública, não pode se tornar um campo de pura relativização de problemas e fenômenos, instalando estudos onde a luta entre teorias contrárias e as supostas inovações pósestruturalistas sirvam de justificativas para uma espécie de anarquismo metodológico, que levam sujeitos envolvidos com o processo de produção do conhecimento no meio acadêmico-científico, a driblar as programações institucionais, ao não respeito ao planejamento e aos cronogramas de investigação, e em alguns casos, a um descompromisso com a prestação de contas relacionadas aos resultados da pesquisa. A pesquisa e os seus resultados são bens públicos, e devem ser comunicados e socializados por meio dos veículos disponíveis institucionalmente.

O conhecimento produzido na Universidade é um bem público, que deve ser usado para o ensino e a produção de novos estudos e pesquisas nas diversas áreas de atuação, não pode ficar restrito ao exercício vaidoso de individualidades que anunciam a desconstrução paradigmática e o fim das regras de construção do conhecimento em educação, como se fossem profetas dadaístas de um novo horizonte pragmático, sem história, sem filosofia, sem matriz, "contra o método". 
Uma projeção de pesquisa em educação pautada no meio acadêmicocientífico, que pretenda a sua sobrevivência, seja na Graduação, seja na PósGraduação, seja no Grupo de Pesquisa, deve ser encarada como trabalho formal e institucional, que exige de quem pesquisa (entra no jogo), a construção de uma estratégia teórico-conceitual, onde por meio de ações estruturadas e sistemáticas, onde se busca o estudo das teorias que permitam a compreensão dos conceitos centrais com relação ao objeto a ser estudado e a relação desses conceitos com o caminho que será percorrido para desvendar o problema relativo ao fenômeno em foco.

Enfim, venha o pesquisador (aluno ou docente) de qualquer aquarela, pintado de qualquer tinta - seja clérigo, militante ou profeta de qualquer tendência material ou mítica de caráter moderno/estruturalista ou pósmoderno/pós-estruturalista - entrou no tempo-espaço da Universidade para fazer pesquisa, o mesmo pode até debater, negar, confirmar, criticar, afrontar, mas, sem seguir as regras estruturantes da teoria e dos métodos ficará clamando no deserto, e não fechara trabalhos que passem pelos meios de avaliação e validação de sua produção acadêmica, essa é realidade concreta.

Ressaltamos que a síntese científica, dentro das regras da construção do conhecimento válido, não precisa ser uma resposta estática a um problema de pesquisa. O Grupo de Pesquisa PAIDEIA constrói conhecimento válido em educação a partir da "matriz paradigmática" (Gamboa, 2012), evidenciando a contradição - substância da dialética (luta de contrários), onde nada está isolado e separado - as matrizes são dinâmicas e movimentam contradições que remetem a sínteses lógicas, mas, inventivas e abertas a novos investimentos da crítica.

Silvio S. Gamboa (2012) esclarece que: o pesquisador deve conhecer as diversas formas de articulação lógica dos enfoques epistemológicos ou abordagens metodológicas para saber o alcance de suas opções e avaliar as implicações e limitações dos modelos de investigação utilizados.

Sendo assim, sem uma ciência (episteme) do caminho (método) de uma pesquisa, onde, o gradiente teórico-metodológico não seja construído devidamente e compatibilizado epistemologicamente, a produção do 
conhecimento válido pode resultar em doxa para animar relatos e discursos espontâneos, movidos a "modismos contemporâneos" na área de educação, mas, sem os avanços esperados por uma projeção dentro do meio acadêmico-científico, que obrigatoriamente devem apresentar resultados em relação ao estudo de um problema, seja por um caminho de caráter indutivo ou dedutivo.

Segundo Gamboa (2012, p. 70):

Para entender os métodos utilizados na investigação científica, é necessário reconstruir os elementos que a determinam e as relações que estes têm com outras dimensões implícitas nos processos de produção do conhecimento, tais como as técnicas, os instrumentos de aquisição, organização e análise de dados e informações e as concepções epistemológicas e filosóficas nas quais se fundamentam os processos de investigação; dimensões essas que supõem uma articulação entre si, uma coerência interna e uma lógica própria, que, por estarem implícitas no processo de elaboração da pesquisa, precisam ser reveladas ou reconstituídas.

Hoje, a necessidade de demandar um tempo específico de atenção à reconstrução dos elementos em torno dos métodos enfrenta algumas resistências no cotidiano de nosso trabalho na Universidade, resistências estas, que reforçam uma espécie de secundarização, quando tentamos colocar o método como temática de estudo e aprofundamento junto a alguns sujeitos que projetam e desenvolvem pesquisas como Bolsistas de Iniciação Científica e Bolsistas de Pós-Graduação, alguns desses alunos, em geral, priorizam ações de busca bibliográficas para compor um bom referencial teórico-conceitual, para dar suporte à projeção da investigação de um problema no contexto dos fenômenos educacionais, e em alguns momentos, nesse início do processo de pesquisa, o método e sua fundamentação epistemológica ficam realmente em segundo plano.

Registro para ilustrar a situação, três trechos de depoimentos recolhidos durante um Grupo Focal, por ocasião da coleta de dados sobre Grupos de Pesquisa em Educação: 1) “O método é uma preocupação do positivismo de Comte, o importante mesmo é ir logo construindo primeiro a pesquisa bibliográfica para revisar a literatura do estudo. No meu caso, só 
depois é que vou ver o método" (Mestrando); 2) "Estou em uma pesquisa qualitativa na I. C., e quase não tratamos de método. Até meu orientador de TCC não liga muito para essa coisa de método. Ela diz que é coisa de positivistas, coisa da burocracia de direita da Universidade, mas, eu fico na minha..." (Bolsista de Iniciação Científica); 3) "Existe realmente uma superficialidade na hora de teorizar sobre o método, na verdade ficamos presos aos procedimentos de coleta de dados, a instrumentalização da pesquisa. Pode ser preconceito mesmo, porque debater método, nos remete ao positivismo... temos que pensar sobre isso" (Docente/Doutorando)

Não podemos deixar de acrescentar ao debate, algumas questões relativamente conhecidas no meio acadêmico científico, que dizem respeito a esse sintoma preconceituoso em torno da questão do método e as barreiras levantadas, que tomam por base enfoques do senso comum sobre o paradigma positivista, as teses de Feyerabend (Contra o método) e os modismos de uma suposta pós-modernidade a brasileira, que circulam em nosso ambiente acadêmico-científico, e remetem alguns desavisados a prática de uma espécie de anarquismo metodológico, comprometendo o plano e o cronograma de pesquisas que em boa parte movimentam recurso público, em forma de bolsas e ambiente estruturado com refrigeração, equipamentos eletrônicos e a imaterial demanda humana cognitiva das relações que se travam em prol da construção do conhecimento em educação.

Para Bernard Charlot (2006, p. 5):

O discurso científico não é o discurso de opinião. Não somos obrigados a fazer pesquisa com qui-quadrados, nem a fazer pesquisa ação, mas, se optamos por fazer à primeira, há normas estatísticas a respeitar, o que não consiste (como se supõe com frequência) emergir e dizer que fazemos pesquisa porque refletimos e escrevemos sobre a ação que fazemos. Existem normas de produção científica. Elas são diversas em relação a alguns pontos, por vezes são até conflitantes, mas essas normas existem. Se não há regras, ou se não há uma comunidade para controlá-las, não há pesquisa, há uma conversa de botequim sobre a educação. 
Em uma pesquisa científica, que é o tipo de pesquisa que realizamos no espaço formal da Universidade, as regras são instituídas e não existe condição material de transitar nesse ambiente na pele do cordeiro puroingênuo (teológico), que acha que vai construir monografia para concluir curso de Graduação, de Pós-Graduação ou Relatório Final no meio acadêmico, sem enfrentar a objetividade necessária para a construção de estudos válidos em educação, o que requer como substância dessa caminhada, a disciplina, para estudar e investigar sistematicamente teorias para uma boa demonstração de literatura e as teorizações que elucidem a episteme dos métodos, no sentido de alcançar com consistência os objetivos de um projeto de pesquisa, desvendando certezas e expondo contradições em forma de sínteses, essa é a condição real de quem faz parte de um ambiente de pesquisa em busca de produzir conhecimento, agora aqueles que submetem às questões em educação ao anarquismo das regras, certamente terão como culminância uma série de problemas que podem deixar marcas na trajetória pessoal e no campo profissional, e seguirão engrossando a "conversa de botequim" que pode ser configurada em militância, messianismo, busca de santidade e outros discursos esferográficos e tautológicos.

Mas, apesar de tantos modismos e da necessidade de "vigilância epistemológica" permanente, Gamboa (2012, p. 87), nos aponta que: a formação do pesquisador tem sofrido diversas influências ao longo das últimas décadas. No primeiro momento (treinamento técnico do pesquisador: Procedimentos estatísticos e desenhos experimentais ou quase experimentais). Hoje: cresce uma maior preocupação com os aspectos metodológicos, teóricos e epistemológicos da investigação em educação.

E um dos caminhos para pesquisar e produzir o conhecimento válido em educação, que vem sendo devidamente atualizado por novos estudos e pesquisas de estudiosos do Brasil e da América Latina foi apontado por Gamboa com a categorização de "Matriz Paradigmática":

Para constatar e interpretar os mais importantes pressupostos epistemológicos, implícito nos métodos utilizados nas investigações, foi utilizada como instrumento organizador uma matriz paradigmática (a 
unidade básica de análise paradigmática é sempre um processo de produção do conhecimento, o qual se dá em todo processo de investigação que inclui: conteúdos filosóficos, lógicos, epistemológicos, teóricos, metodológicos e técnicos que "implicam modos de atuar" (Gamboa, 2012, p. 39)

Como ponto de partida desse caminho dialético - a pergunta, que dá início ao núcleo dinâmico do exercício filosófico, gera o problema de pesquisa e movimenta o início de uma projeção de estudo. Da boa pergunta podemos construir uma boa pesquisa e dar início a análise crítica de um objeto de estudo em educação. O jogo de perguntas e respostas deve se dirigir a um problema central e questões norteadoras em torno do mesmo. "Pesquisamos problemas" (Gamboa, 2010).

Cultivar o problema (a questão da questão), problematizar é remontar de um conjunto de questões ordenadas até ao problema constitutivo do tema, é deslindar o próprio cerne de uma interrogação e de um questionamento ordenado. A problematização das questões é o momento filosófico por excelência, porque nos faz alcançar algo radical, em conexão com nosso ser-no-mundo (Russ, 2010, p. 37).

\section{Considerações finais}

Procuramos chamar a atenção nesta exposição para o "cultivo" da episteme dos métodos. A questão da ciência do método é tarefa da filosofia no seu campo de conteúdos epistemológicos. Quando em nosso cotidiano, secundarizamos o estudo dos fundamentos do método, deixamos de lado os elementos que movimentam a pesquisa em sua dimensão política, social e cultural - porque é na trajetória da pesquisa que travamos relações com os sujeitos da busca de obras de uma biblioteca as diversas formas de coletas de dados no campo empírico, por esse motivo a necessidade de um conhecimento aprofundado das abordagens epistemológicas e matrizes que fundamentam o caminho do estudo de fenômenos em educação.

Quanto à análise crítica do método, Gamboa (2012, p. 47) destaca que: a crítica do método segue sendo um dos papéis fundamentais da filosofia; sua presença é necessária no estágio atual da pesquisa em 
educação que, num processo de reflexão sobre a prática e de aprofundamento qualitativo, pretende ampliar as linhas de 'investigações sobre investigações.

Por fim, vamos para além dos modismos que buscam dominar o cotidiano do meio acadêmico-científico, seguir as regras históricas da construção do conhecimento por meio da abordagem crítico-dialética, pelo seu caráter político contrário ao absolutismo das certezas científicas, e favorável as sínteses concretas, históricas, inventivas e abertas as dinâmicas da criticidade, desenvolvendo nossos projetos de pesquisa em educação, considerando e atribuindo a importância devida tanto ao repertório conceitual que servirá de suporte ao nosso quadro teórico bem como ao fundamento conceitual que estabelece a episteme (a ciência) do método (caminho), para que a construção do conhecimento válido não vire um exercício de elaboração de "discurso espontâneo", mas, que tenha assegurada a sua natureza científica e a sua dimensão política, social e cultural por meio do trabalho que realizamos na área de educação nas nossas Universidades.

\section{Referências}

ADORNO, T. W.; HORKHEIMER, M. Dialética do esclarecimento: fragmentos filosóficos. Rio de Janeiro: Jorge Zahar, 1985.

BRANQUINHO, João; MURCHO, Desidério (org) - Enciclopédia de termos lógico-filosóficos. Lisboa: Gradiva, 2001.

CHARLOT, Bernard. A Pesquisa Educacional entre Conhecimentos, Políticas e Práticas: especificidades e desafios de uma área de saber. Revista Brasileira de Educação, v. 11, n. 31, jan/abr, 2006.

COMTE-SPONVILLE, André - Dictionnaire philosophique. Paris: Presses universitaires de France, 2001.

KOSIK, K. Dialética do Concreto. 7. Ed. Rio de Janeiro: Paz e Terra, 2002.

PAIXÃO, Carlos Jorge. Caminhando no território da História. ESTUDOS Humanidades - Revista da Universidade Católica de Goiás - UCG, Goiânia, v. 30, n. 3, p. 445-453, mar., 2003.

RUSS, Jacqueline. Os métodos em filosofia. Petrópolis - RJ: Vozes, 2010. 
SÁNCHEZ GAMBOA, Silvio. Análise Epistemológica dos Métodos na Pesquisa Educacional. Brasília, UNB, Dissertação de Mestrado, 1982.

SÁNCHEZ GAMBOA, Silvio. Alternativas metodológicas em el ejercício de La investigación educativa. In: Educação e Sociedade, São Paulo, 1984, (19), 91 111.

SÁNCHEZ GAMBOA, Silvio. Epistemologia da Pesquisa em Educação. Campinas, UNICAMP, Tese de Doutorado em Educação, 1987.

SÁNCHEZ GAMBOA, Silvio. Pesquisa em Educaşão: métodos e epistemologias. Chapecó: Argos, 2008.

SÁNCHEZ GAMBOA, Silvio. Epistemologia da educação física: as inter-relações necessárias. 2. Ed. Maceió: EDUFAL, 2010.

SÁNCHEZ GAMBOA, Silvio. Pesquisa em Educaşão: métodos e epistemologias. 2. Ed. Chapecó: Argos, 2012.

SÁNCHEZ GAMBOA, Silvio. A Dialética na Pesquisa em Educação: elementos de contexto. In: FAZENDA, I. Metodologia da Pesquisa Educacional. São Paulo: Cortez, 1993.

SÁNCHEZ GAMBOA, Silvio. Las Categorias de tiempo e historicidad em los actuales enfoques de La historiografia educativa em Brasil. In: CUCUZZA, Hector Ruben (Org.). Historia de La Educación en debate. Buenos Aires: Miño y Davila, 1996.

SÁNCHEZ GAMBOA, Silvio. Fundamentos para La investigación educativa: presupuestos epistemológicos que orientan al investigador. Santa Fé de Bogotá: Cooperativa Editorial Magisterio, 1998.

SÁNCHEZ GAMBOA, Silvio. Pesquisa Educacional na Universidade da Amazônia: compromisso regional no contexto do conflito das globalizações. In: PAIXÃO, C. J. (Org.). Educação e Conhecimento na Amazônia. Belém: Editora UNAMA, 2004.

SANTOS FILHO, José Camilo dos.; GAMBOA, Silvio Sánchez. Pesquisa Educacional: quantidade-qualidade. 4. Ed. São Paulo: Cortez, 2001. 